\title{
Quantification, Games and Existence
}

\author{
Hiroshi Endo \\ Waseda University, Tokyo
}

\section{§1. Language games of seeking and finding}

Of various language games, in which verbs for quantifiers can occur, one is taken up by Hintikka as of utmost importance, i.e. the language games of seeking and finding, as he calls it." The game is played by a proponent whom we can take to be ourselves and his opponent, who may be simply nature or some recalcitrant malin genie making the most of his chances of frustrating the proponent. The proponent's end is to make true a substitution instance of the matrix of the prenex normal form of a given formula, whereas the opponent aims at making the outcome of the game to be false substitution instance of the matrix. For each existential quantifier it is the proponent that chooses an individual whose name is to be substituted for the corresponding bound variable, and for each universal quantifier does the opponent make the choice of an individual. In case the proponent has a winning strategy in the game correlating to a given sentence, the sentence is true.

For Hintikka the meaning of quantifiers being primitive, our comprehending of it through formulation pressupposes on the meta-level the understanding of the meaning of quantifiers. Therefore learning how to play the language games for quantifiers is the only way to know the meaning or the so-called logical behavior of quantifiers.

Now, the choice to be made by the proponent as well as the response to the opponent's choice is according to Hintikka the end-point of search, i.e. the outcome of seeking and finding. This means that it is not necessary for us to know beforehand what individuals there are in a domain, in so for as we are not Platonists who are required always to have such knowledge. Often the boundaries of the field of search are vague and ambiguous and so is the meaning of the corresponding quantified sentence. As for the end-point of search, the case of being able to point to a physical object or to a man, is indeed the paradigmatic case which the other cases shade into.

§2. Model sets

For this theory of the language game of seeking and finding to stand on a solid scafolding, we must take into consideration Hintikka's theory of model sets 
which bears analogy with the theory of language games. ${ }^{2}$ Model sets are consistent sets of first-order sentences which are to be regarded as partial descriptions of logically possible states of affairs (possible courses of events, possible worlds) and sets of model sets are called model systems. Contrary to the impression the word 'model' is likely to give, the quantification here developed is not objectual but substitutional. So, as Quine indicates, the question of ontological commitment may not properly arise in this theory of model sets, except that the theory is expressed in classical quantificational form, or in so far as one has in mind how to translate it into that form. ${ }^{3)}$ But a closer examination about the model sets may bring to light the situation we are confronting.

The following example shows how a counter example is constructed by a language game and brings about inconsistency in a model set $M$ with the result of amplifying $M$ with a new sentence. Suppose the proponent proposes that $Q(b)$ (which means that $b$ exists) is a member of $M$, then $(E x)(x=b)$ (which Hintikka proposes as a formal substitute for existance of $b$ ) is also a member of $M$. Because, if $\mathrm{Q}(\mathrm{b}) \epsilon \mathrm{M}$ and $(\mathrm{x}) \sim(\mathrm{x}=\mathrm{b}) \epsilon \mathrm{M}$, then by the opponent's choosing of $\mathrm{b}$ for the bound variable $x$ the proponent is forced to admit $\sim(b=b)$ into $M$, which is contradictory to $b=b$ already involved in $M$, since $M$ is so constructed that for each singular term which occurs in $M, M$ contains its self-identity. Thus (Ex) $(x=b)$ is admissible into $M$.

In connection with such model sets the undecidability of quantification theory can be interpreted to say that one cannot always predict how far one would have to go in an attempted model set construction in order to bring out the possible inconsistency which may lurk in the set which we are trying to imbed in a model set. The unpredictability lies in the process of a model set construction just as in the process of seeking and finding veiled in ambiguity. Now, the substitutional quantification is as much different from objectual quantification as countable sets from uncountable ones, but it seems to me that the logic of the Language lurks in language itself, so that between two types of quantifications there is not so much a gap as a continuance, one phase of which is the game of seeking and finding.

\section{§3. Exist vs. subsist}

The end-point of search is existence, but $(\mathrm{Ex})(\mathrm{x}=\mathrm{b})$ in the above example has place in Hintikka's first order language at the remotest nook from existence, because I believe it better to regard $(\mathrm{Ex})(\mathrm{x}=\mathrm{b})$ as a formal-linguistic substitute for subsistance rather than existence of $b$. This is to be shown below.

Let $P(b)$ (" $b$ is $P$ ") and $\sim P(b)$ respectively take the place of $Q(b)$ in the above discussion about the validity of $Q(b) \rightarrow(E x)(x=b)$. Then, we have $P(b) \rightarrow$ (Ex) $(x=b)$ and $\sim P(b) \rightarrow(E x)(x=b)$ as valid with respect to $M$. Therefore, both $\sim(\mathrm{Ex})(\mathrm{x}=\mathrm{b})$ and $\sim \mathrm{P}(\mathrm{b})$ do not belong to a same model set, because from $\sim \mathrm{P}(\mathrm{b})$ 
$\rightarrow(\mathrm{Ex})(\mathrm{x}=\mathrm{b}), \sim \mathrm{P}(\mathrm{b})$ conflict with $\sim(\mathrm{Ex}) \quad(\mathrm{x}=\mathrm{b})$. However, contraposition holds in every model set. So $\sim(\mathrm{Ex})(\mathrm{x}=\mathrm{b}) \rightarrow \sim \mathrm{P}(\mathrm{b})$ with respect to $\mathrm{M}$. Seen from $M, \sim(E x)(x=b)$ is a description of a possible state of affair, so it belongs to some model set alternative to $M$ in the model system. As far as we see from the world the description of which is $\mathrm{M}, \mathrm{b}$ exists and at the same time does not exist in a possible world.

Even though domain reference function is given to the quantifier, as is proposed by Rescher, we cannot find our way out of this paradoxical predicament, which turns out to be the conflict between $\left(\mathrm{E}_{2} \mathrm{x}\right)(\mathrm{x}=\mathrm{b})$ and $\left.\sim\left(\mathrm{E}_{2} \mathrm{x}\right)(\mathrm{x}=\mathrm{b}) .^{4}\right)$

In order to avoid this predicament, each model set must be such an exhaustive description in which every individual occurs. To this corresponds for instance the atomistic conception of the world, as indicated by Thomason's interpretation of his model structure. ${ }^{5}$ ) As $\mathrm{P}(\mathrm{b}) \vee \sim \mathrm{P}(\mathrm{b})$ holds in such an extended model set, we have by dilemma (Ex) $(x=b)$, which shows that $(E x)(x=b)$ is a formallinguistic substitute for subsistance of $b$.

The most important and difficult problem with regards to possible worlds is, it seems to me, not to make a survey of any one of them, but to know to what extent one is responsible for another. So considered, language is also a possible world, and the problem is to what extent the periphery of language is invading or otherwise invaded by the external world. Seen from within language existence holds, so to speak, in such vagueness of the periphery. In view of Fisk's semantics of strength, an interpretation of one world is sometimes so strong as to make the world shrink to naught.6) To use this diction of Fisk's, the interpretation of existence given in a formal language is perhaps too strong for existence. If I say this the other way round, what existence requires of us at the end-point of search is as meager an expression as possible.

§4. Dialogue and hermeneutics

In Lorenzen's concept of a language game its dialogical characteristic comes strongly into the foreground.7) Singular terms, predicates, predicates of predicates,.... and so on are introduced into ortholanguage (a language to be taught) by means of paralanguage (a language used by a teacher in the teaching process). That is to say, the rules to move from an atomic sentence to an atomic sentence originate from a dialogue and the meanings of logical connectives and quantifiers are also learned through dialogues between a proponent and an opponent.

Here distinguishing several possible worlds deviates from the point. Unlike Hintikka, Lorenzen does not adopt the method of counter examples, which leads to classical logic and accordingly subsistance of $b$ in the above argument. It is for intuitionistic logic that his dialogical games lay the foundation. Here both 
$\mathrm{P}(\mathrm{b}) \rightarrow(\mathrm{Ex})(\mathrm{x}=\mathrm{b})$ and $\sim \mathrm{P}(\mathrm{b}) \rightarrow(\mathrm{Ex})(\mathrm{x}=\mathrm{b})$ hold, but the conjunction of these does not yield $(E x)(x=b)$. Furthermore it must be noted that $(E x)(x=b)$ does not dialogically imply $Q(b)$.

The language game of seeking and finding takes the phase of dialogical construction of logic on the substitutional level and also the phase of the hermeneutical articulation of the outer world. Namely, the ortholanguage is the outcome of hermeneutical construction, which absorbs through seeking and finding a certain always already (immer schon) given sense of the extralinguistic world, and which developes dialecticaly, taking its course in a dialectical spiral, i.e. hermeneutical circulation.

§5. The meaning of existence in hermeneutical circulation

Apel says, "Der Umstand, daß die Kopula ("etwas ist etwas") als Ausdruck der "hermeneutischen Synthesis" ("etwas als etwas sein lassen") verstanden werden kann, enthält wiederum einen Hinweis darauf, daß sie auch mit dem "ist" der Identitätsbehauptung eine gemeinsame Bedeutungswurzel haben dürfte."8) Hermeneutical circulation is re-interpretation in which hermeneutical synthesis and judgement of identity co-exist, whereas, both having a common root of meaning, as Apel suggests, is not the hermeneutical synthesis essentially circular? Our form of life is nothing but reiteration of such synthesis. Thus, from the viewpoint of hermeneutics existence is Seinlassen involving identity, which at the remotest extreme of the aforementioned continuance might bring forth the identity expression, such as $(\mathrm{Ex})(\mathrm{x}=\mathrm{b})$. But existence always evades such an expression. Even an immaginery map says something of the world, the moment we correlate a point in the map with a place on the globe. $(\mathrm{Ex})(\mathrm{x}=\mathrm{b})$ is one of the points in the immaginery map, while hermeneutically existence is the correlating, and hence it can not itself possibly occur in any map.

\section{References}

1) Hintikka, J., "Language-Games for Quantifier" Studies in Logical Theory, American Philosophical Quarterly, Monograph series (ed. by N. Rescher), Oxford, 1968, P. 46ff.

2) Hintikka, J., Models for Modalities, D. Reidel, 1969 P. 24f, P. 57f, P. $114 f$.

3) Quine, W.V., "Existence and Quantification", Fact and Existence (ed. by J. Margolis) Blackwell, 1969, P. 12f.

4) Rescher, N., Topics in Philosophical Logic, D. Reidel, 1968, P. 156f.

5) Thomason, R.H., "Modal Logic and Metaphysics", The Logical Way of Doing Things (ed. by K. Lambert) Yale Univ. Press, 1969, P. 127.

6) Fisk, M., "A Modal Analogue of Free Logic", The Logical Way of Doing Things, P. $180 \mathrm{ff}$.

7) Lorenzen, P., Normative Lagic and Ethics, Bibliographisches Institut, Mannheim/ Zürich, 1969, P. $21 \mathrm{ff.}$

8) Apel, K.-O., Transformation der Philosophie, Band I Sprachanalytik, Semiotik, Hermeneutik, Suhrkamp, 1973, S. 245, Anm. 36. 